\title{
Good Practices Pelayanan Kesehatan : Inovasi Pelayanan Kesehatan Di Daerah**
}

\author{
Oleh : M. Rizki Pratama*
}

*Alumnus Prodi Ilmu Administrasi Negara FISIP UNAIR

*Paper ini telah dikirimkan dalam lomba blog FPKR (Forum Peduli Kesehatan

Rakyat) dengan tema "Wajah Sistem dan Regulasi Kesehatan di Indonesia" pada tahun 2013

Jujur saja pelayanan kesehatan bagi masyarakat di Indonesia masih banyak mengalami masalah yang membuat pelayanan yang diberikan menjadi buruk, sebagai fakta bahwa Indonesia berada pada peringkat ke-100 dunia sebagai negara dengan kesenjangan perbedaan yang tinggi antara anak keluarga kaya dan miskin dalam mengakses layanan kesehatan. ${ }^{1}$ Ditambah lagi salah satu indikator yang penting kita perhatikan dalam menilai kualitas kesehatan suatu negara adalah IPM (indeks pembangunan manusia) atau dikenal dengan HDI (human development index) yang memuat indikator usia harapan hidup, akses terhadap pendidikandan standar hidup yang layak. HDI Indonesia pada tahun 2012 adalah 0,629 dengan posisi peringkat ke-121 dari 187 negara bersama Kiribati dan Afrika Selatan. HDI Indonesia di bawah nilai 0,64, yaitu nilai HDI rata-rata kelompok negara dengan IPM medium dan di bawah nilai 0,683 yaitu nilai rata-rata negara di Asia Timur dan Pasifik. ${ }^{2}$ Jadi sangat terbukti pelayanan kesehatan di Indonesia masih stagnan dan dibawah rata-rata jika ingin disebut memiliki pelayanan kesehatan yang berkualitas.

Terus mengungkit buruknya pelayanan publik terutama pelayanan kesehatan masyarakat di Negara ini memang tidak ada habisnya akan tetapi sedikit pencerahaan dalam tulisan ini akan membuka mata kita bahwa ada praktik-praktik yang baik (good practices) melalui inovasi pelayanan kesehatan yang dilakukan oleh berbagai elemen pemerintah di daerah yang pada akhirnya mampu meningkatkan kualitas pelayanan kesehatan bagi masyarakat. Peningkatan yang dilakukan tidak

\footnotetext{
${ }^{1}$ http://www.metrotvnews.com/indonesiamemilih/read/2013/09/03/92/179306/IndonesiaNegara-dengan Kesenjangan-Kesehatan-Tinggi (diakses tanggal 11/12/13)

2 Zaenal Abidin. 2013, Problem Struktural Pembangunan Kesehatan Indonesia, http:/ / m.koran sindo.com/node/343875 (diakses tanggal 11/12/13)
} 
sekedar meningkatkan pelayanan kepada masyarakat akan tetapi juga membentuk suatu sistem baru baik dari dalam lembaga maupun perubahan sosial. Inovasi memiliki dampak penting dalam perubahan suatu pelayanan publik terutama untuk memotong alur yang panjang dan berbelit-belit layaknya birokrasi pada umumnya. Inovasi juga mampu merubah kebiasaan masyarakat ataupun persepsi masyarakat pada suatu pelayanan publik, jika dahulu menganggap pelayanan publik sangat rumit dan sulit melalui inovasi pelayanan mereka dapat mendapatkan hal-hal baru yang tidak pernah mereka alami sebelumnya. Dalam pelayanan kesehatan inovasi pelayanan juga memegang peranan penting bagi terselenggaranya pelayanan kesehatan dari pemerintah kepada masyarakat untuk dapat menjadi better (lebih baik), cheaper (lebih murah) dan faster (lebih cepat). Menurut Wijayanti ${ }^{3}$ pemerintah harus melakukan inovasi untuk mencari cara baru bagi pemecahan masalahmasalah lama, mempergunakan sumber daya secara lebih efisien dan memenuhi kebutuhan-kebutuhan baru serta memperbaiki strategi dan taktik. Sejauh ini telah banyak pemerintah daerah melakukan berbagai inovasi pelayanan kesehatan akan tetapi juga tidak semuanya berhasil dalam melakukannya. Berbagai inovasi yang dihasilkan oleh pemerintah daerah dalam pelayanan kesehatan juga membuktikan keseriusan pemda dalam memberikan pelayanan kepada masyarakatnya sebab menciptakan inovasi tidaklah mudah, membutuhkan kemauan yang kuat dari pemerintah untuk dapat mengkreasinya sebab dengan adanya inovasi pelayanan kesehatan dimungkinan dapat merugikan pihak-pihak yang selama ini berbuat curang dalam penyelenggaraan pelayanan, adanya inovasi pelayanan akan memeutus rantai penyalahgunaan wewenang. Budaya korupsi yang tengah menjalar di pelayanan publik dapat dibabat untuk menghasilkan pelayanan yang lebih lagi bagi masyarakat.

Osborne dan Brown ${ }^{4}$ mengungkapkan bahwa innovation is a introduction of newness into a system usually, but not always, in relative terms and by the application (and occasionally invention) of a new idea. This produces a process of transformation that brings

\footnotetext{
${ }^{3}$ Sri Wahyu Wijayanti. 2008, Inovasi Pada Sektor Pelayanan Publik. Jurnal Administrasi Publik. Vol. IV (4), Hal 41

${ }^{4}$ Stephen P. Osborne dan Kerry Brown. 2005, Managing Change And Innovation In Public Service Organization. New York: Routledge, hal. 116
} 
about a discontinuity in terms of the subject itself (such as a product or service) and/or its environment (such as an organization, market or a community). Menurut Osborne inovasi merupakan pengenalanan sesuatu yang baru ke dalam sebuah sistem, akan tetapi tidak selalu seperti itu, dalam keadaan tertentu dan dengan aplikasi (seringkali invensi) dari sebuah ide baru. Inovasi tersebut menghasilkan sebuah proses transformasi yang membawa sesuatu yang terputus dari subjeknya (seperti produk atau layanan) dan atau lingkungannya (seperti organisasi, pasar atau komunitas). Inovasi merupakan upaya menambahkan sesuatu yang baru dalam sistem-sistem yang sudah ada, jadi inovasi dipastikan berbeda dengan invensi atau penemuan baru, terminologi inovasi juga menunjukkan bahwa setiap upaya yang dilakukan tidak akan merubah total suatu sistem yang sudah ada akan tetapi hanya menambahkan hal-hal yang baru kepada sub-bagian sistem yang ada untuk diupgrade menjadi lebih baik. Dalam pelayanan kesehatan maka inovasi yang dilakukan dapat terjadi di seluruh sub-sistem yang ada yang terkait dengan sistem pelayanan kesehatan, jadi inovasi mensyaratkan kondisi yang baik pada nilai-nilai organisasi yang tengah melakukan inovasi karena inovasi juga merupakan hasil dari segala tindakan positif untuk menciptakan daya saing. Dalam inovasi pelayanan kesehatan pasti menggunakan pendekatan baru yang lebih baik daripada sebelumnya, konsep konsep baru dikembangkan dalam pelayanan kesehatan misalnya kemitraan dalam pelayanan kesehatan, penggunaan teknologi informasi dalam pelayanan kesehatan serta berbagai terobosan lainnya. Inovasi harus menghasilkan dampak yang lebih baik daripada pelayanan sebelumnya. Inovasi pelayanan kesehatan juga sudah seharusnya memapu memberikan peningkatan pelayanan kesehatan bagi masyarakat jika persyaratan tersebut tidak berhasil dilakukan maka inovasi dianggap mubazir dan tidak layak disebut dengan inovasi.

\section{Inovasi dan Kualitas Pelayanan Kesehatan}

Inovasi pelayanan membuat pelayanan publik lebih baik jika diselenggarakan dengan baik pula, jangan sampai inovasi hanya mengikuti trend saja sehingga akan mati kemudian. Inovasi harus berkelanjutan sehingga inovasi dapat berubah-ubah 
sesuai dengan kebutuhan dan perkembangan masyarakat. Menurut Hartley ${ }^{5}$ "There is an important difference in innovation between private and public sectors. In the private sector, successful innovation is often seen to be a virtue in itself, as a means of ensuring competitiveness, whether in new markets or to revive flagging markets. This is not the case for public services, where innovation is justifiable to the extent that it increases public value in the quality, efficiency or fitness for purpose of governance or services." Inovasi pelayanan sangat dekat dengan kualitas pelayanan karena dapat memperkuat nilainilai publik misalnya dalam kualitas pelayanan ataupun efisiensi. Lynn ${ }^{6}$ lebih lengkap lagi mengungkapkan innovation must not simply be another name for change, or for improvement, or even for doing something new lest almost anything qualify as innovation. Innovation is properly defined as an original, disruptive, and fundamental transformation of an organisation's core tasks. Innovation changes deep structures and changes them permanently. Inovasi tidak sesederhana perubahan atau peningkatan ataupun melakukan sesuatu yang baru yang hampir memenuhi kualifikasi inovasi. Inovasi merupakan transformasi yang orisinil, disruptif dan fundamental dari tugastugas inti organisasi.

Inovasi pelayanan kesehatan di berbagai pemerintah daerah membuktikan bahwa menghasilan perubahan pelayanan kesehatan kepada masyarakat yang lebih baik. Inovasi mampu menghadirkan perubahan di dalam organisasi dan memaksanya untuk berbuat lebih baik atau sebaliknya organisasi yang baik akan mampu menciptakan berbagai inovasi pelayanan. Adanya inovasi pelayanan kesehatan pada suatu institusi juga membuktikan adanya kemauan keras dari dalam organisasi kesehatan untuk berbuat lebih baik, sebab menciptakan inovasi pelayanan tidaklah mudah, organisasi yang mampu memandang diri sendiri sebagai pelayan masyarakatlah yang mampu menciptakan inovasi yang sulit untuk dirinya sendiri akan tetapi bermanfaat bagi masyarakat luas. Sulit bagi organisasi kesehatan jika hanya berorientasi pada tugas-tugas pokok saja untuk meningkatkan kualitas pelayanan kesehatan, akan tetapi dengan menciptakan inovasi pelayanan

\footnotetext{
${ }^{5}$ Jean Hartley. 2006, Innovation And Its Contribution To Improvement : A Review For Policy Maker, Policy Advisers, Managers And Researchers. London : Departement For Communities And Local Government, hal. 41

${ }^{6}$ Ibid, hal. 25
} 
kesehatan maka kualitas pelayanan yang didapat oleh masyarakat akan meningkat dengan sendirinya jika inovasi pelayanan kesehatan dianggap berhasil oleh masyarakat sebagai penerima jasa pelayanan kesehatan.

\section{Urgensi Inovasi Pelayanan Kesehatan}

Di tengah kondisi pelayanan kesehatan yang masih buruk tentu saja sangat mendesak untuk dilakukannya inovasi pelayanan kesehatan dengan kemampuan inovasi pelayanan yang mampu memetong berbagai alur yang berbelit-belit sudah jelas inovasi harus dipandang sebagai hal yang positif. Mulgan dan Albury ${ }^{7}$ menyebutkan beberapa alasan mengapa sektor publik harus melakukan inovasi, yaitu : 1) Untuk merespon secara lebih efektif perubahan dalam kebutuhan dan ekspetasi publik yang terus meningkat, 2) Untuk memasukkan unsur biaya dan meningkatkan efisensi, 3) Untuk memperbaikki penyelenggaraan pelayanan publik, termasuk di bagian-bagian yang pada masa lalu hanya mengalami sedikit kemajuan, 4) Untuk mengkapitalisasi penggunaan ICT secara penuh : hal ini dikarenakan penggunaan ICT telah terbukti meningkatkan efisiensi dan efektivitas dalam penyelenggaraan pelayanan.

Pada era global seperti saat ini dimana perubahan sangat cepat terjadi maka sudah sangat terlambat dan merugikan masyarakat jika tidak dilakukan inovasi pelayanan. Inovasi Pelayanan kesehatan memberikan kesempatan dan kecepatan yang lebih baik kepada masyarakat. Kebutuhan pelayanan kesehatan masyarakat yang semakin cepat berubah dan tidak diikuti dengan perubahan pelayanan dari organisasi maka kerugian kesehatan masyarakat akan semakin besar dan yang paling fatal adalah turunnya kesehatan masyarakat hingga meninggal dunia, oleh karena itu inovasi harus dilakukan dengan menyesuaikan tuntutan dan kebutuhan masyarakat. Inovasi pelayanan kesehatan akan menjangkau kebutuhan kesehatan masyarakat secara lebih efektif dan efisien karena menembak setiap kebutuhan masyarakat secara tepat dan tidak membuang-buang energi dan anggaran. Inovasi

\footnotetext{
7 Dalam Sri Wahyu Wijayanti. 2008, Inovasi Pada Sektor Pelayanan Publik. Jurnal Administrasi Publik. Vol. IV (4), hal. 42
} 
pelayanan kesehatan harus diselenggarakan jika tidak nasib masyarakat di masa mendatanglah yang akan dipertaruhkan.

\section{Transformasi Pelayanan ODHA Di Kota Kediri}

Inovasi pelayanan kesehatan yang dilakukan oleh pemerintah Kota Kediri ini memberikan perubahan peayanan kepada para ODHA (orang dengan HIV AIDS). Memang tidak banyak pemerintah daerah yang konsen terhadap penanganan ODHA. Melalui inovasi ini pemerintah Kota Kediri mampu mengendalikan jumlah penderita dan merubah persepsi masyarkat agar mereka tidak merasa dikucilkan sehingga inovasi pelayanan disini tidak hanya menangani kesehatan dari ODHA sendiri akan tetapi juga memberikan resolusi permasalahan sosial yang mereka alami. Transformasi pelayanan di sini ditujukan untuk menangani dan mencukupi kebutuhan daripada ODHA itu sendiri. Point terpenting disini adalah memberikan akses layanan kesehatan yang mudah didapatkan ODHA di kota Kediri. Sedangkan adanya transformasi itu sendiri yang diawali dari pembuatan perwali (peraturan Walikota) dibuat agar menjadi pedoman ataupun arahan peran dan tugas yang jelas bagi penyedia layanan untuk memberikan layanan yang benar-benar mudah diakses dan jauh dari diskriminasi. Output yang ingin dicapai disini adalah agar tidak terulang kasus - kasus ODHA yang kurang terlayani dengan baik. ${ }^{8}$

\section{Yes 118 : Mekanisme Pelaporan Dan Penanganan Gawat Darurat Medis Kota Yogyakarta}

Sering kali UGD (unit gawat darurat) ruamh sakit terlalu lamban unutk menangani korban sehingga meningkatkan resiko meninggal dan cacat. Melalui inovasi ini pemerintah daerah Kota Yogyakarta mengitegrasikan sistem pelayanan UGD melalui panggilan di hotline 118. Penanganan UGD pun dirubah bahkan biaya ditanggung oleh pemerintah Kota Yogyakarta pada 24 jam pertama. Mekanisme aduan masyarakat melalui YES 118 telah memberikan jaminan masyarakat melaporkan kejadian gawat darurat medis dan mendapatkan penanganannya

\footnotetext{
8 Paksi J.Wiseso, Parji, M. Kozin. 2012, Database Good Practice : Transformasi Pelayanan ODHA Menuju Pelayanan Komprhensif Di Kota Kediri. Yogyakarta : University Network For Governance Innovation, hal. 2
} 
dengan mudah dan cepat melalui jaminan ambulan gratis serta jaminan pelayanan 24 jam pertama di rumah sakit sesuai dengan ketentuan. Sistem yang disiapkan dalam YES 118 selama 24 jam memungkinkan setiap aduan diterima dan ditindaklanjuti dengan segera. Setiap laporan masyarakat akan segera ditindaklanjuti berkat adanya sistem informasi dan hospital mapping yang terpadu. Berdasarkan data pelapor, operator YES 118 akan melacak lokasi kasus terlapor untuk segera mengirimkan bantuan evakuasi, pelayanan medis dan rujukan ke rumah sakit terdekat dari lokasi kejadian. Hal ini meminimalisir keterlambatan pertolongan akibat masalah mekanisme aduan masyarakat seperti nomor telepon rumah sakit sulit dihubungi, rumah sakit jauh dari lokasi kejadian, armada ambulan sedang digunakan atau petugas ambulan tidak ada di tempat. ${ }^{9}$

Segala bentuk inovasi pelayanan kesehatan yang dilakukan oleh pemerintah daerah wajib kita apresiasi jika memang menimbulkan dampak positif, jika justru dampak negatif yang diberikan maka wajib kita kritisi dengan bijak. Inovasi pelayanan kesehatan sudah seharusnya memberikan dampak positif bagi peningkatan pelayanan kesehatan bagi masyarakat, studi kasus di Kota Kediri membuktikan bahwa perlu adanya pelayanan khusus bagi penderita ODHA sehingga mengurangi resiko penularan kemudiaan di Kota Yogyakarta menunjukkan UGD harus memiliki respon yang cepat dan tanggap sehingga inovasi pelayanan untuk merespon masyarakat yang mengalami bantuan gawat darurat dapat segera ditangani untuk mengurangi resiko cacat dan meninggal dunia. Semoga inovasi pelayanan kesehatan dapat dilakukan di seluruh pemerintah daerah indonesia agar masyarakat mendapatkan manfaatnya dan mungkin saja juga terjadi proses replikasi dari contoh dua inovasi pelayanan kesehatan di atas mengingat sudah teruji keberhasilannya. Indonesia yang sehat dan sejahtera adalah impian seluruh masyarakat Indonesia, salah satu cara yang harus dilakukan adalah meningkatkan kualitas pelayanan kesehatan, baik melalui inovasi pelayanan kesehatan ataupun melalui perubahan positif lainnya.

\footnotetext{
${ }_{9}^{9}$ Martino. 2012. Database Good Practice : Yes 118 Mekanisme Pelaporan Dan Penanganan Gawat Darurat Medis Kota Yogyakarta. Yogyakarta : University Network For Governance Innovation, hal. 8
} 


\section{Daftar Pustaka}

Abidin, Zaenal. 2013, Problem Struktural Pembangunan Kesehatan Indonesia, http://m.koran sindo.com/node/343875 (diakses tanggal 11/12/13)

Hartley, Jean. 2006, Innovation And Its Contribution To Improvement : A Review For Policy Maker, Policy Advisers, Managers And Researchers. London : Departement For Communities And Local Government.

http://www.metrotvnews.com/indonesiamemilih/read/2013/09/03/92/179306/I ndonesia-Negara-dengan Kesenjangan-Kesehatan-Tinggi (diakses tanggal $11 / 12 / 13)$

Martino. 2012, Database Good Practice : Yes 118 Mekanisme Pelaporan Dan Penanganan Gawat Darurat Medis Kota Yogyakarta. Yogyakarta : University Network For Governance Innovation.

Osborne, Stephen P. dan Kerry Brown. 2005, Managing Change And Innovation In Public Service Organization. New York : Routledge.

Wijayanti, Sri Wahyu. 2008, Inovasi Pada Sektor Pelayanan Publik. Jurnal Administrasi Publik. Vol. IV (4).

Wiseso, Paksi J., Parji, M. Kozin. 2012, Database Good Practice : Transformasi Pelayanan ODHA Menuju Pelayanan Komprhensif Di Kota Kediri. Yogyakarta : University Network For Governance Innovation. 